\title{
Tensile Properties of As-Cast Aluminum Alloys AA3104, AA6111 and CA31218 at Above Solidus Temperatures
}

\author{
A. B. Phillion ${ }^{1}$, S. Thompson ${ }^{2}$, S. L. Cockcroft ${ }^{2}$, and M. A. Wells ${ }^{3}$ \\ ${ }^{1}$ Computational Materials Laboratory, EPF-Lausanne, Lausanne, Switzerland \\ ${ }^{2}$ Department of Materials Engineering, University of British Columbia, Vancouver, Canada \\ ${ }^{3}$ Department of Mechanical and Mechatronics Engineering, University of Waterloo, Waterloo, \\ Canada
}

\begin{abstract}
The semi-solid tensile mechanical response of three as-cast aluminum alloys - AA3104, AA6111, and CA31218 (an alloy similar in composition to AA3003) - was measured between a fraction solid $f_{\mathrm{s}} \sim 0.85$ and $f_{\mathrm{s}} \sim 1$ in order to establish the mushy zone constitutive behavior under conditions similar to those believed to occur during Direct Chill casting. The fraction solid vs. temperature relationship for these alloys is also provided. The constitutive behavior appears greatly dependent on both fraction solid and strain rate. Furthermore, while the behavior is dominated by the solid network, the critical fraction solid for complete loss of ductility was found to be alloy dependent, ranging from $f_{\mathrm{s}} \sim 0.94$ for CA31218 to $f_{\mathrm{s}} \sim 0.99$ for AA6111. The variation in both ductility and stress with temperature has been used to propose a brittle temperature range for each of the three alloys and to rank their hot tearing susceptibility.
\end{abstract}

\section{Introduction}

In the direct chill (DC) casting of aluminum alloys, the primary and secondary cooling regimes impose strong thermal gradients on the ingot or billet. These thermal gradients invariably lead to the generation of stresses and accumulation of strain within material in the semi-solid state, and contribute to the formation of solidification defects such as hot tearing, porosity, and surface liquation. In order to improve quality, a number of DC casting thermalmechanical process models have been developed ${ }^{[1-6]}$. These models require as input the constitutive behavior of the material being cast across a wide temperature range, including the semi-solid. Within the mushy state at high fraction solid, the material is extremely weak and exhibits little or no ductility. The semi-solid stress/strain behavior is of critical importance, since it allows for accurate simulation of the formation of stresses and strains during the casting process, and thus will aid in predicting solidification defects.

The constitutive behavior of semi-solid as-cast material is complex, due to variables such as fraction solid, porosity, grain size, structure of the solid network, viscosity of the liquid, impurities, etc. The reader is referred to Eskin et al. [7] for further details regarding the semisolid microstructure-ductility-stress relationship. Because of this complexity, and in order to determine constitutive behavior well-suited for the simulation of DC casting, a number of 
constraints are imposed on the required experimental data. Firstly, the test conditions should be similar to those that prevail during DC casting in terms of the microstructure and strain rate. Secondly, the tests should be conducted under tensile loading conditions because the formation of hot tearing-type defects is as a result of tensile stresses.

Semi-solid tensile experiments are difficult to conduct, because of the combination of low stresses, low ductility, and high temperatures. However, a number of relevant experimental results have been reported. Singer and Cottrell ${ }^{[8]}$ provided the early measurements of semi-solid properties, on a series of Al-Si alloys. The strength of the material was found to drop to zero at temperatures between five to sixty degrees above the solidus, depending on the alloy composition. Colley et al. ${ }^{[9]}$ investigated the semi-solid tensile properties of DC cast AA5182 using a diametral strain measurement. Two critical transitions were reported: the temperature of zero-ductility occurring at $\sim 565^{\circ} \mathrm{C}$, and the temperature of zero-stress occurring at $\sim 570^{\circ} \mathrm{C}$. Phillion et al. ${ }^{[10]}$ also measured the semi-solid tensile properties of DC cast AA5182, but found slightly lower transition temperatures for the as-cast material, with zero-ductility at $\sim 548^{\circ} \mathrm{C}$ and zero-stress at $\sim 560^{\circ} \mathrm{C}$. Furthermore, the transitions were found to be highly dependent on microstructure. Van Haaften et al. ${ }^{[11]}$ conducted semi-solid tensile tests on both DC cast AA3104 and DC cast AA5182. Strain rate sensitivity was observed at all temperatures up to $550^{\circ} \mathrm{C}$, above which the tensile strength became very small. Twite et al. ${ }^{[12]}$ measured the semisolid tensile properties of three AA6061 alloys from different sources: laboratory DC cast, commercially DC cast and thixocast. The results showed that tensile strength and ductility of the laboratory cast and commercially cast specimens were similar, while the properties of the thixocast alloy were lower than the other two. Kron and Fredriksson ${ }^{[13]}$ have also measured the semi-solid tensile properties of AA6061, but reported significantly lower critical transitions. Fabrègue et al. [14] investigated the mechanical behavior of AA6056 with and without grain refiner, and reported that a transition was observed between fracture in the mushy state and fracture in the solid state as a function of strain rate. Several key conclusions can be drawn from the above prior work. Firstly, it appears that material loses all ductility at a fraction solid, $f_{\mathrm{s}}$ $\sim 0.95-0.98$, and loses all strength at $f_{\mathrm{s}} \sim 0.90-0.95$. Secondly, the semi-solid constitutive behavior is highly dependent on solid grain morphology, and the composition of the alloy. Thirdly, the choice of strain measurement (i.e. either diametral $[9,11]$ or lengthwise strain $[8,10$, $12,13])$ is important since the change in ductility is associated with temperature is significant. 
The use of a lengthwise strain measurement may lead to a ductility which is the average value based on a range of temperatures instead of a specific value at a specific temperature.

Mitchell et al. ${ }^{[15]}$ have recently undertaken a study to characterize strain localization during cooling from the liquid state in three aluminum alloys - AA3104 (beverage cans), AA6111 (automotive applications), and CA31218 (brazing applications). It was found that semi-solid AA3104 was able to sustain twice the amount of macroscopic strain prior to localization as compared to AA6111, and nearly four times as compared to CA31218. This corresponds to the industrial experience related to the castability and hot tearing susceptibility of these alloys. However, the semi-solid constitutive behavior of these alloys remains largely unknown.

The aim of the present study is to characterize the semi-solid constitutive behavior of AA3104, AA6111, and CA31218, and to investigate their hot tearing susceptibility. To this end, tensile tests have been carried out at solid fractions above $\sim 0.85$, and a critical temperature range for hot tearing is proposed.

\section{Experimental}

\subsection{Materials and Specimen Geometry}

The composition of the materials investigated in this study, AA3104, AA6111, and CA31218, are provided in Table 1 . Note that CA31218 is a proprietary alloy similar in composition to AA3003 but containing significantly higher amounts of $\mathrm{Cu}$ and $\mathrm{Mg}$, and slightly lower amounts of Mn. These alloys were supplied by Rio Tinto Alcan - Arvida Research and Development Centre, located in Jonquiere, Quebec. Cylindrical tensile specimens with a gauge length of 100 $\mathrm{mm}$ and a diameter of $8 \mathrm{~mm}$ were machined directly from DC-cast ingots and were therefore in the as-cast state. The longitudinal orientation of these specimens was parallel to the rolling face, and perpendicular to the casting direction to facilitate the application of load to the as-cast structure in an orientation consistent to that found to produce hot tears in DC cast rolling ingots.

\subsection{The relationship between fraction solid and temperature}

The evolution of fraction solid with temperature is an important quantity when performing semi-solid constitutive behavior measurements. This can be determined either experimentally using techniques such as differential scanning calorimetry ${ }^{[16]}$, and two-thermocouple cooling ${ }^{[17]}$, or via solidification models such as the Scheil equation or the Alstruc model ${ }^{[18]}$. Unfortunately, it is inherently difficult to reliably characterize the fraction solid curve of industrial alloys under DC casting conditions. This is because small changes in alloy composition create different 
eutectic/intermetallic phases, which results in a different evolution in fraction solid in proximity to the solidus temperature. Generally, the experimentally-determined results at high fraction solid differ from one publication to the next. For example, Aliravci et al. ${ }^{[19]}$ reported a solidus temperature ( $T_{\text {solid }}$ ) of $\sim 580{ }^{\circ} \mathrm{C}$ for AA6111, while Chen et al. ${ }^{[20]}$ reported a value of $\sim 475^{\circ} \mathrm{C}$. Similarly, Bäckerud ${ }^{[21]}$ reported $T_{\text {solid }} \sim 470^{\circ} \mathrm{C}$ for AA5182, while Thompson et al. ${ }^{[17]}$ reported a value of $\sim 520^{\circ} \mathrm{C}$.

The solidification models also have difficulty with the high fraction solid regime. In the case of the Scheil equation, the exclusion of back diffusion into the solid grains depresses the solidus temperature by including low melting eutectic phases in the numerical calculation. Aliravci et al. ${ }^{[19]}$ have shown that the fraction solid curves predicted by Thermo-Calc for AA5182 using the Scheil equation are significantly different from those determined experimentally via a cooling-curve technique. Chen et al. ${ }^{[20]}$ carried out a comparative study, of AA6111 determined experimentally via a two-thermocouple technique to Scheil-Gulliver predictions, an equation which includes some back diffusion into the solid. They also noted that the two methods produced significantly different fraction solid - temperature relationships at high fraction solid.

In the current research, the solidus temperature and fraction solid curves have been provided by Alcan ${ }^{[22]}$. The data for AA6111 and AA3104 are based on experimental measurements acquired using a two-thermocouple technique for a cooling rate of $\sim 1.5 \mathrm{~K} \mathrm{~s}^{-1}$. Although these curves may differ from earlier published sources, the use of these curves ensures consistency between the two alloys. Unfortunately, similar data was not available for CA31218. In this case, the curve predicted by a thermodynamic model, Thermo-Calc, has been used.

\subsection{Mechanical Testing}

The semi-solid tensile tests were carried out using a low force Instron mechanical testing unit attached to a Gleeble 3500 thermomechanical simulator to provide rapid electrical Joule heating. Full details of this apparatus are provided elsewhere ${ }^{[9]}$. Each test specimen was secured in a vertical orientation between two water-cooled grips (one grip is free to allow for thermal expansion), and was heated at $1 \mathrm{~K} \mathrm{~s}^{-1}$ to the test temperature. Once the test temperature was reached, a $30 \mathrm{~s}$ hold was applied to allow for a steady-state thermal gradient to develop prior to tensile deformation.

Approximately 60 tensile tests were conducted at temperatures between $475-625^{\circ} \mathrm{C}$, and at strain rates of $\sim 10^{-3}$ and $\sim 10^{-4} \mathrm{~s}^{-1}$. The ultimate tensile strength (UTS) was calculated by 
converting the maximum force recorded during testing by a $4.5 \mathrm{kN}$ load cell to a stress based on the original cross-sectional area: $\sigma_{\text {UTS }}=\left(F / A_{0}\right)$. The failure strain was measured post-test using Vernier calipers based on the diametral change at the point of fracture: $\varepsilon_{\text {fail }}=-2 \ln \left(D / D_{0}\right)$. A high-resolution dilatometer was not used due to concerns that the force required to close its jaws would be greater than the weak semi-solid compressive strength of the alloy. Furthermore, it was decided to forego a non-contact measurement method after preliminary tests showed very little difference in the diameter measured using a high-speed digital camera versus the Vernier calipers.

\section{Results}

\subsection{Fraction Solid}

As described in Section 2, the determination of fraction solid curves for industrial alloys is challenging due to the high number of different solute elements and their corresponding eutectic and intermetallic phases.

The experimentally-derived fraction solid curves for AA3104 and AA6111, and the modelderived fraction solid curve for CA31218 are shown in Fig. 1 and Table 2. Only the region relevant to the semi-solid tensile experiments, i.e. $f_{\mathrm{s}}>0.8$, has been provided. The three alloys have significantly different behavior. Firstly, the solidus temperature for these alloys varies between 483 and $573^{\circ} \mathrm{C}$. Secondly, the temperature range over which the last $5 \%$ of the liquid solidifies varies from $43^{\circ} \mathrm{C}$ for AA3104, to $85^{\circ} \mathrm{C}$ for CA31218, to $117^{\circ} \mathrm{C}$ for AA6111. Thirdly, the behavior of the final phase(s) is quite different in the three alloys, with AA6111 exhibiting a long freezing range over which the last 1-2\% liquid solidifies. Thus, due to the large variations in the solidification of the final liquid, these alloys would be expected to have significantly different hot tearing behavior.

The fraction solid curves for AA3104 and AA6111 can also be predicted by a thermodynamic model. A comparison between the experimental and model fraction solid curves for these two alloys is provided in Fig. 2. As can be seen in Fig. 2(a), the two curves for AA6111 are quite dissimilar, with the model predicting a much lower fraction solid for a given temperature over the range examined. Also, at $501^{\circ} \mathrm{C}$, the model predicts solidification of a very small amount of classical eutectic, defined by a unique solidification temperature. In contrast, the experiment shows that the last liquid solidifies over a large range of temperatures, leading to a solidus 
temperature of $483^{\circ} \mathrm{C}$. The two curves for AA3104 are shown in Fig. 2(b). As can be seen from this figure, the model once again under-predicts the fraction solid at a given temperature over the range examined but the error is smaller than for alloy AA6111. The model also does a good job in predicting the eutectic solidification and the solidus temperature. It is difficult to draw any conclusion as to the potential error in the model derived data for CA31218 based on the comparisons of Fig. 2(a) and (b) as the error will be alloy dependent. However, since the model predicts similar amounts of eutectic in both AA3104 and CA31218, the error resulting the use of a model-based fraction solid curve is estimated to be similar to the error observed for AA3104 in Fig. 2(a), i.e. on the order of $10^{\circ} \mathrm{C}$ at high fraction solid.

\subsection{Semi-Solid Constitutive Behavior}

The results for the semi-solid tensile deformation experiments conducted on AA3104, AA6111 and CA31218 are shown in Figs. 3-5. In each graph, the UTS and failure strain are provided as a function of temperature for both strain rates examined. The solidus temperature $\left(f_{\mathrm{s}}\right.$ $=1.0)$ and the temperature corresponding to $f_{\mathrm{s}}=0.90$ are also shown for reference. The relationship between the constitutive behavior and fraction solid will be discussed further in Section 4.

As can be seen in these three figures, both the UTS and failure strain show a general trend of decreasing value with increasing temperature, between a flow stress of $\sim 18 \mathrm{MPa}$, and failure strain of $\sim 1.3$ at $480^{\circ} \mathrm{C}$ for AA6111 (Fig. 4) to a flow stress of $\sim 0.5 \mathrm{MPa}$ and a failure strain of $\sim 0$ at $630^{\circ} \mathrm{C}$ for CA31218 (Fig. 5). Over the range of temperature examined, both properties appear to have three distinct regimes of behavior. At the low end of the temperature range, and extending a short distance into the two phase region, these alloys exhibit a gradual reduction in both the UTS and failure strain with increasing temperature. At a critical temperature, there is a change in behavior characterized by a rapid decrease in the mechanical properties. Above this temperature, the semi-solid material has a small flow stress and can sustain only limited strain prior to failure ${ }^{1}$.

These three regimes of semi-solid deformation occur as a result of the distribution of the liquid phase within the microstructure. Near the solidus, the liquid exists as isolated pockets at grain triple points, and has only a limited effect on the mechanical properties. The drop in both

\footnotetext{
${ }^{1}$ Note that there is reported to be an increase in apparent ductility at even higher temperatures, with lower fraction solid, due to mass feeding and the ability to transport liquid [23].The exploration of this regime is beyond the capability of the current experimental equipment.
} 
the UTS and failure strain is largely influenced by the behavior of the solid and hence the response with increasing temperature is similar to that of the fully solid material. This behavior has allowed the utilization of creep-law type semi-solid constitutive equations in the past [24, 11 , 25]. As the temperature increases, the liquid pockets begin to interconnect to form a continuous film around the grains, resulting in a steep reduction in constitutive behavior. The first effect is a steep decrease in the failure strain, which is generally followed at a higher temperature by a drop in the load capacity of the semi-solid as the liquid films between grains thicken. From the standpoint of hot tearing, which occurs during cooling, the key features are the temperature and fraction solid at which the semi-solid material first exhibits load bearing capacity, referred to below as the critical stress temperature, and the temperature at which the semi-solid material can sustain strain prior to failure, referred to below as the critical ductility temperature. These key temperature / constitutive behavior features are summarized in Table 3. As seen in Figs. 3-6, and Table 3, these two key features do not always occur at the same temperature or fraction solid.

\section{a. AA3104}

Fig. 3 shows the semi-solid stress and ductility properties of AA3104. Beginning with the load bearing capacity, it can be seen that the critical stress temperature occurs at approximately $620^{\circ} \mathrm{C}$ for $\dot{\varepsilon} \sim 10^{-3} \mathrm{~s}^{-1}$ and $615^{\circ} \mathrm{C}$ for $\dot{\varepsilon} \sim 10^{-4} \mathrm{~s}^{-1}$. Below this temperature, the UTS rapidly increases with decreasing temperature. Both the fully-solid and semi-solid stress response exhibit a strain rate sensitivity, since the experiments performed at $\dot{\varepsilon} \sim 10^{-3} \mathrm{~s}^{-1}$ have a much higher UTS as compared to $\dot{\varepsilon} \sim 10^{-4} \mathrm{~s}^{-1}$. At the solidus temperature, the UTS was $20 \mathrm{MPa}$ for the high strain rate case, and $14 \mathrm{MPa}$ for the lower strain rate case. The ductility was also found to be sensitive to strain rate, with values of 0.4 and 0.7 at the solidus for the high and low strains rate cases. Furthermore, the critical ductility temperature was found to be $610^{\circ} \mathrm{C}$ for $\dot{\varepsilon} \sim 10^{-3} \mathrm{~s}^{-1}$ and $615^{\circ} \mathrm{C}$ for $\dot{\varepsilon} \sim 10^{-1} \mathrm{~s}^{-1}$.

\section{b. AA6111}

The semi-solid constitutive behavior for AA6111 is shown in Fig. 4. First of all, it is clear from comparing Figs. 3 and 4, that the temperature range between $f_{\mathrm{s}}=0.90$ and $f_{\mathrm{s}}=1$ is much larger in the case of AA6111. The results for stress show a dependence on temperature similar to that observed with AA3104. However, for AA6111, the critical stress temperature was found to occur at approximately $580^{\circ} \mathrm{C}$ and was independent of the strain rate. The critical ductility temperature was found to occur at approximately $530^{\circ} \mathrm{C}$ at $\dot{\varepsilon} \sim 10^{-3} \mathrm{~s}^{-1}$, and $560^{\circ} \mathrm{C}$ at $\dot{\varepsilon} \sim 10^{-4} \mathrm{~s}^{-1}$. 
Thus, for the higher strain, there is a $50^{\circ} \mathrm{C}$ difference in temperature between the onset of loadbearing capacity and the ability to sustain strain prior to failure. Comparing the stresses at the solidus temperature, it is observed that the UTS was $17 \mathrm{MPa}$ for $\dot{\varepsilon} \sim 10^{-3} \mathrm{~s}^{-1}$, and $15 \mathrm{MPa}$ for $\dot{\varepsilon}$ $\sim 10^{-4} \mathrm{~s}^{-1}$. The fully solid material has previous been shown to be strain rate sensitive ${ }^{[26]}$ and hence these results are consistent with earlier findings.

\section{c. CA31218}

The semi-solid constitutive behavior for CA31218 is shown in Fig. 5. As with AA6111, alloy CA31218 has a very large temperature range between $f_{\mathrm{s}}=0.90$ and $f_{\mathrm{s}}=1$. However, CA31218 has a significantly different semi-solid mechanical response, with much higher critical stress and ductility temperatures. In this alloy, the critical stress temperature was found to occur at approximately $630^{\circ} \mathrm{C}$ and was independent of the strain rate. The critical ductility temperature was found to occur at $610^{\circ} \mathrm{C}$ for $\dot{\varepsilon} \sim 10^{-3} \mathrm{~s}^{-1}$, and $630^{\circ} \mathrm{C}$ for $\dot{\varepsilon} \sim 10^{-4} \mathrm{~s}^{-1}$. At temperatures below the critical ductility point, the ductility was found to be highly dependent on strain rate.

\section{Discussion}

The experimental data presented in Figs. 3-5 clearly shows the variation in UTS and failure strain of AA3104, AA6111 and CA31218 in the transition region between fully solid and semisolid material. Qualitatively, these results are in agreement with previous measurements [9, 11, $13,8,12,10]$ on other aluminum alloys, as well as the tensile strengthening mechanism for solidifying aluminum alloys - due to the formation of a continuous solid network at high fraction solid - proposed by previous authors [27, 28]. Quantitatively, the stress results for AA3104 differ by $\sim 50 \%$ as compared to those measured by van Haaften ${ }^{[11]}$. This is probably a result of composition variation between the current specimens and those used by van Haaften, resulting in the measurements at a given temperature corresponding to a different fraction solid. The solidus temperature reported by van Haaften for AA3104 was $535^{\circ} \mathrm{C}$, which is $30^{\circ} \mathrm{C}$ lower than the value in Table 2. The ductility of AA3104, and the semi-solid constitutive behavior for AA6111 and CA31218 has not previously been reported.

The fraction solid data reported in Fig. 1, and the stress/strain data reported in Figs. 3-5 are combined in Fig. 6 for $\dot{\varepsilon} \sim 10^{-4} \mathrm{~s}^{-1}$ to provide the variation in failure strain (Fig. 6a) and UTS (Fig. 6b) as a function of fraction solid. When plotted in this fashion, the difference in behavior of these three alloys is striking as they all exhibit different properties for a given fraction solid. 
Firstly, although the three alloys have significantly different composition, their UTS is relatively similar for $f_{\mathrm{s}}=1$. Secondly, within the experimental range of fraction solid, the failure strain for CA31218 is much higher as compared to AA3104 and AA6111. Thirdly, both the critical ductility point and critical stress point differ between the alloys. The trend in strain to failure observed in this study is exactly opposite to what is experienced in terms of castability from the standpoint of hot tearing, and thus the bulk strain to failure would appear to be a poor indicator of hot tearing susceptibility.

It can be seen in Fig. 6, that the critical ductility occurs at a fraction solid of 0.94, 0.96 and 0.99 for CA31218, AA3104 and AA6111 respectively, while the critical stress occurs at a fraction solid of $0.88,0.95$ and 0.98 . Previous work found that the fraction solid for critical ductility was a constant $f_{\mathrm{s}}=0.95[9,10]$. However, the results shown here indicate that its value varies with composition. This new observation provides evidence that the solidification sequence in the three alloys is quite different, which prohibits AA6111 from forming grain bridges until $f_{\mathrm{s}}$ $=0.98$ while grain bridges form in AA3104 at $f_{\mathrm{s}}=0.95$. One obvious difference between the alloys is the formation of the eutectic phase at the end of solidification. The formation of this phase occurs at a fraction solid which is alloy-dependent, and leads to solid bridges forming between the grains. These solid bridges result in improved semi-solid ductility.

The ability for load-bearing capacity allows stress concentration to occur in certain features of the microstructure, e.g. at triple points, porosity and intermetallics. As shown in Figs. 3-5, each alloy has a unique temperature range between the critical stress temperature and the critical ductility temperature whereby it has load-bearing capacity without the ability to sustain tensile deformation. Thus appreciable stress concentration will lead to material failure. Semi-solid microstructure has previously been shown to undergo four stages - mass feeding, interdendritic feeding, interdendritic separation, and interdendritic bridging - based on the permeability of the solid network [7, 29, 30]. It is proposed that the range between the critical stress temperature and the critical ductility temperature corresponds to the interdendritic separation stage and thus characterizes an alloy's susceptibility to hot tearing. At temperatures below critical ductility, the alloy develops ductility rapidly and is easily able to accommodate tensile deformation. At temperatures above the critical stress, the response to applied load is determined by the behavior of the liquid film surrounding the grains and may be influenced by interdendritic liquid feeding. 
The brittle temperature range for the three alloys are summarized below in Table 3. From the standpoint of castability, it would make sense that an alloy exhibiting a small brittle temperature range would be less prone to hot tearing since this alloy would spend less time within the critical temperature range where there is load bearing capacity without ductility. The results from the present study indicate that $\mathrm{AA} 6111$, with a critical range of $20-50^{\circ} \mathrm{C}$, would be the most prone to hot tearing followed by CA31218 and then AA3104. These results are generally consistent with industrial experience where AA6111 and CA31218 are both know to be hot tear prone alloys in comparison to AA3104. Mitchell et al. ${ }^{[15]}$, in a study of strain accumulation during constrained solidification, also found CA31218 and AA6111 to rank poorly in comparison to AA3104.

The present study has a number of important limitations. Firstly, since the samples are reheated as-cast material, there may be important differences between the mechanical behavior measured in this work and that observed during solidification. For example, feeding is likely not present in the current experiments since deformation occurs in material that is not undergoing solidification and therefore there is no reservoir or pool of liquid metal in close proximity to feed liquid associated with deformation of the semi-solid. Thus the results by Magnin ${ }^{[23]}$, which demonstrate the increase in semi-solid failure strain at temperatures above critical stress, and Farup et al. [28], which showed that the healing of hot tears can occur at relatively high fraction solid, would not be expected to be observed in the present work. The as-cast structure may also undergo partial homogenization during the reheating and tensile testing, with a total test time of 10 minutes. Because of the strong dependence between constitutive behavior and the distribution of the liquid phase, this change in compositional gradient could have an associated effect on the mechanical behavior. The results of Fabrègue et al. [33] provided evidence that mushy zone upon cooling from the liquid contains a greater number of thin interconnected liquid films, and fewer liquid pockets. Thus for a given fraction solid, semi-solid material derived from reheating experiments will contain a greater proportion of solid bridges which will manifest itself as a higher strength. Secondly, it is also possible that the actual semi-solid ductility may be much higher than measured, since the use of a diametral definition for strain does not include the formation of internal damage that may have accumulated within the structure. Previous work by Phillion et al. [34] have found that this internal damage may be as large as $50 \%$ for material at very high fraction solid. Finally, previous work has shown that as-cast porosity has a significant 
impact on ductility ${ }^{[10]}$. While this porosity is present in the as-cast samples, the interplay between late-stage feeding, volumetric shrinkage, strain accumulation and porosity formation and growth is missing in the current approach because the samples are being reheated.

\section{Conclusions}

The semi-solid constitutive behavior of three aluminum alloys AA3104, AA6111, and CA31218, has been established at high fraction solid for use in DC casting process models. The experiments consisted of reheating specimens up to semi-solid temperatures and then applying a tensile deformation until failure. Under these conditions, the constitutive behavior was found to be greatly dependent on both temperature and strain rate. In the context of hot tearing, two critical temperatures have been defined: 1) the critical stress temperature, which is the temperature, during cooling, where the material first begins to exhibit load bearing capacity; and 2) the critical ductility temperature, which is the temperature that the material first begins to exhibit ductility. These temperatures were found to vary greatly between the three alloy. The variation in constitutive behavior between the different alloys as a function of fraction solid was also reported. Under the conditions examined, the fraction solid for zero-ductility was found to be $0.94,0.96$ and 0.99 for CA31218, AA3104 and AA6111 respectively.

As a means of assessing hot tearing susceptibility, the difference in temperature between critical stress and critical ductility has been defined as the brittle temperature range. For the three alloys examined, AA3104 was found to be least likely to exhibit hot tearing with a brittle temperature range less than $10^{\circ} \mathrm{C}, \mathrm{CA} 31218$ was found to be intermediate with a brittle temperature range less than $20^{\circ} \mathrm{C}$ and AA6111 was found to be the most likely with a brittle temperature range between 20 and $50^{\circ} \mathrm{C}$. These alloy-specific brittle temperature ranges may be used to provide improved estimates for a number of hot tearing criteria and process models.

\section{Acknowledgements}

The authors wish to thank Alcan for supplying the experimental materials, fraction solid curves, and financial assistance. The NSERC post-graduate scholarship program is also gratefully acknowledged. 


\section{Figure Headings}

Fig. 1: Fraction solid curves for AA3104 ${ }^{[22]}$ and AA6111 ${ }^{[22]}$ measured with a twothermocouple technique, and for CA31218 predicted using Thermo-Calc.

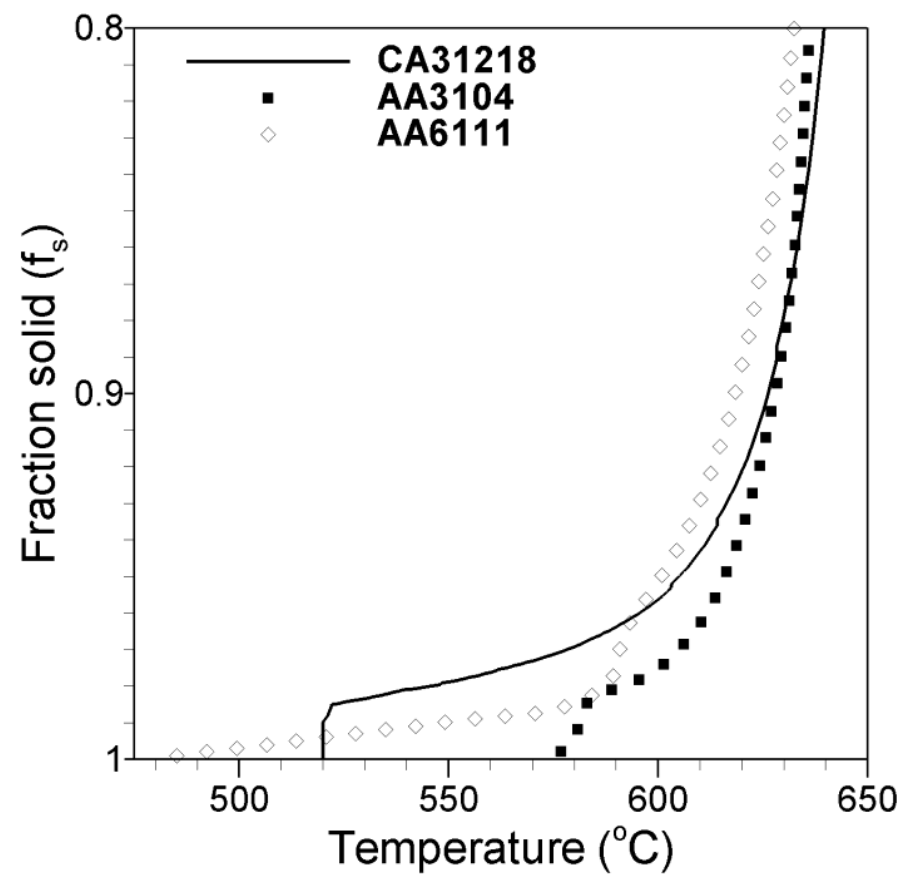


Fig. 2: A comparison between the fraction solid - temperature relationship for AA6111 (a) and AA3104 (b) measured experimentally and predicted using Thermo-Calc.

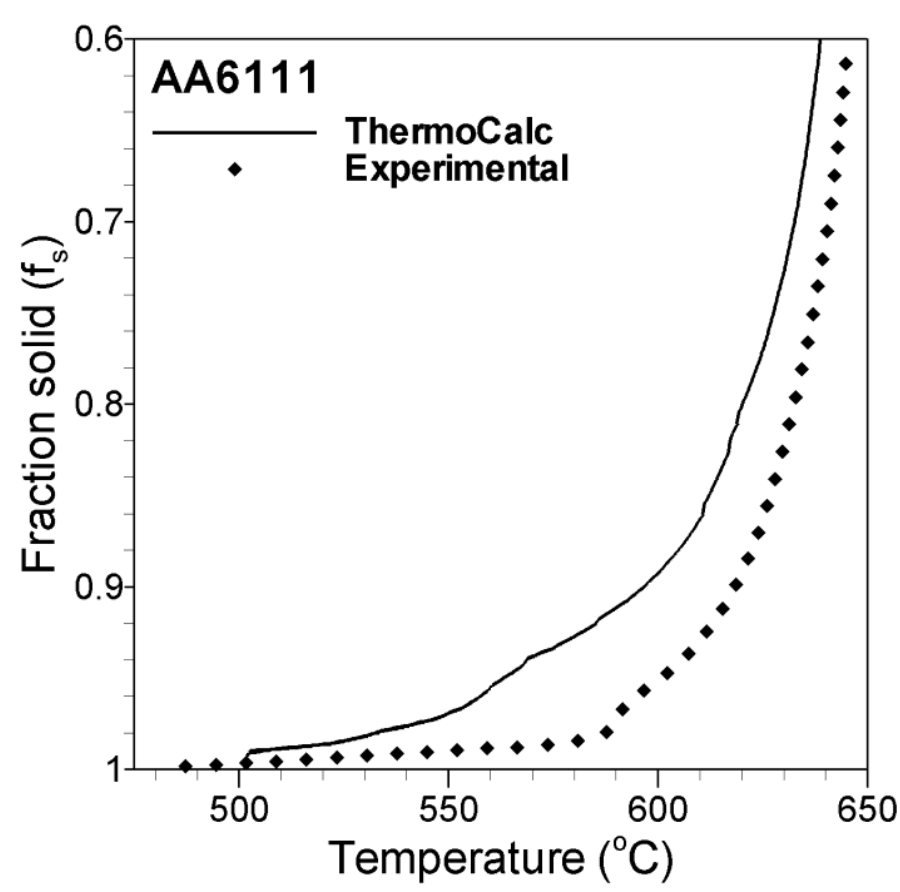

a)

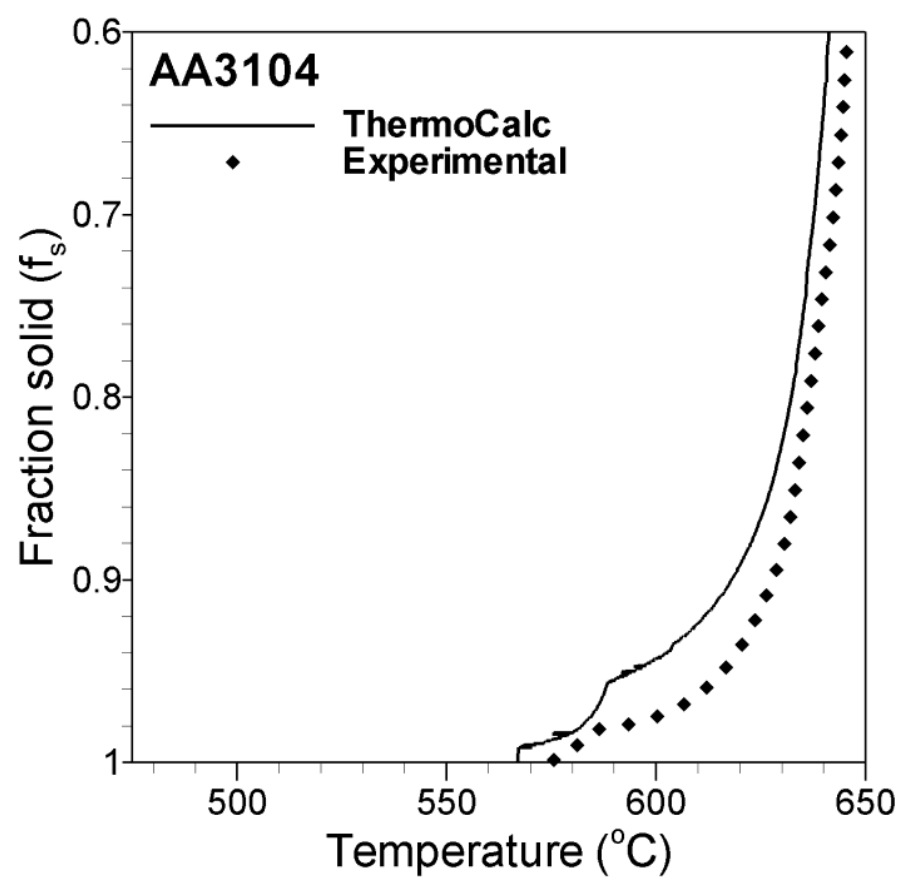

b) 
Fig. 3: Semi-solid outs (symbols) and true failure strain (lines) for AA3104 as a function of temperature at two strain rates: $10^{-3}$ and $10^{-4} \mathrm{~s}^{-1}$. The solidus temperature and the temperature corresponding to $f_{\mathrm{s}}=\mathbf{0 . 9 0}$ is also shown.

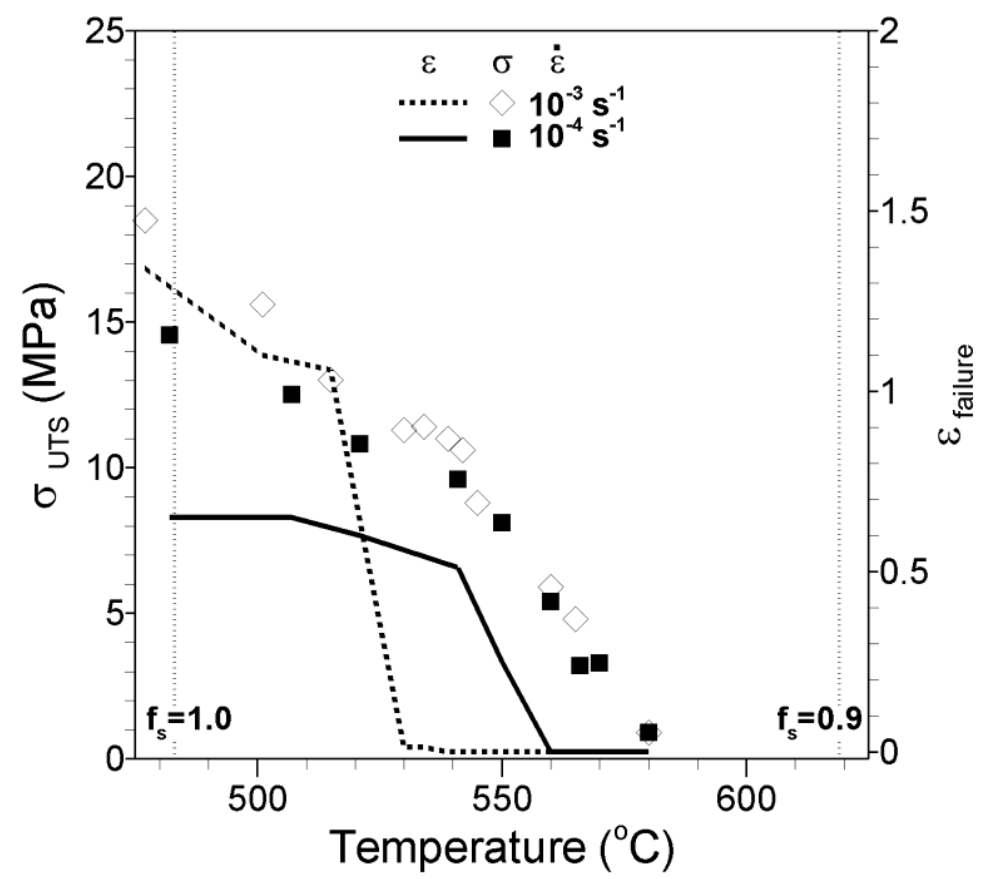

Fig. 4: Semi-solid outs (symbols) and true failure strain (lines) for AA6111 as a function of temperature at two strain rates: $10^{-3}$ and $10^{-4} \mathrm{~s}^{-1}$. The solidus temperature and the temperature corresponding to $f_{\mathrm{s}}=0.90$ is also shown.

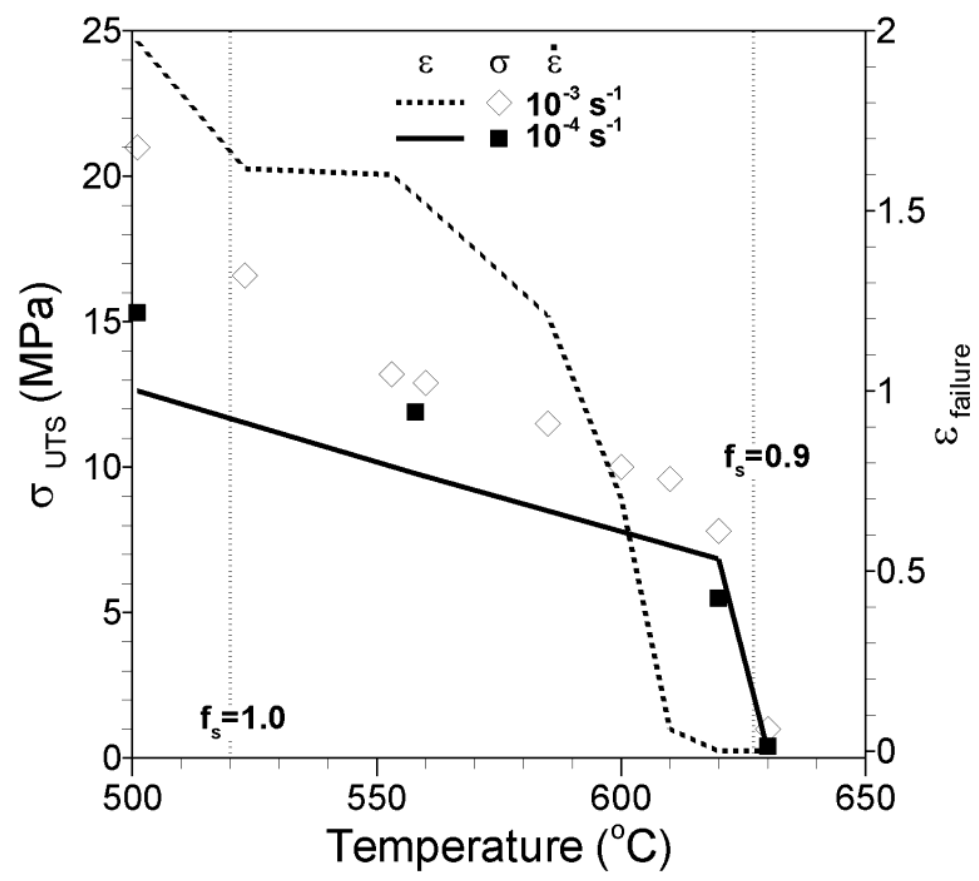


Fig. 5: Semi-solid outs (symbols) and true failure strain (lines) for CA31218 as a function of temperature $10^{-3}$ and $10^{-4} \mathrm{~s}^{-1}$. The solidus temperature and the temperature corresponding to $f_{\mathrm{s}}=\mathbf{0 . 9 0}$ is also shown.

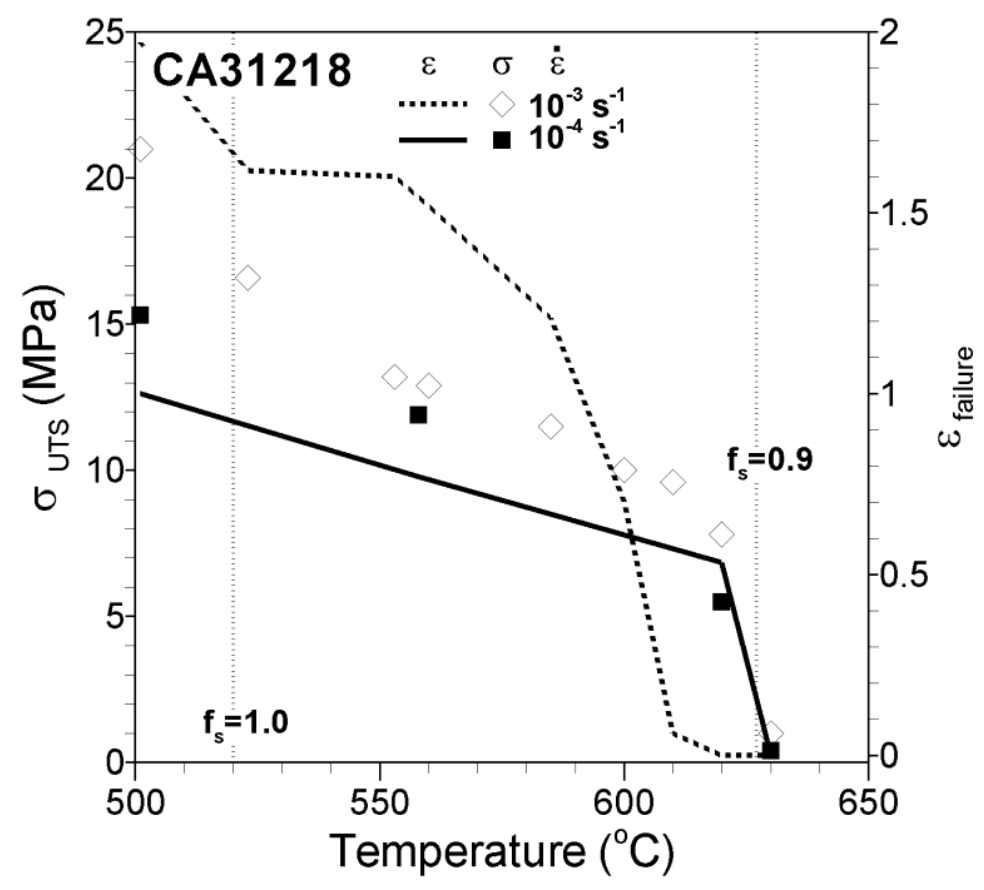


Fig. 6: Constitutive behavior comparison between the four alloys: (a) failure $\left(\dot{\varepsilon} \sim 10^{-4} \mathrm{~s}^{-1}\right)$, and (b) outs $\left(\dot{\varepsilon} \sim \mathbf{1 0}^{-4} \mathrm{~s}^{-1}\right)$ as functions of fraction solid.

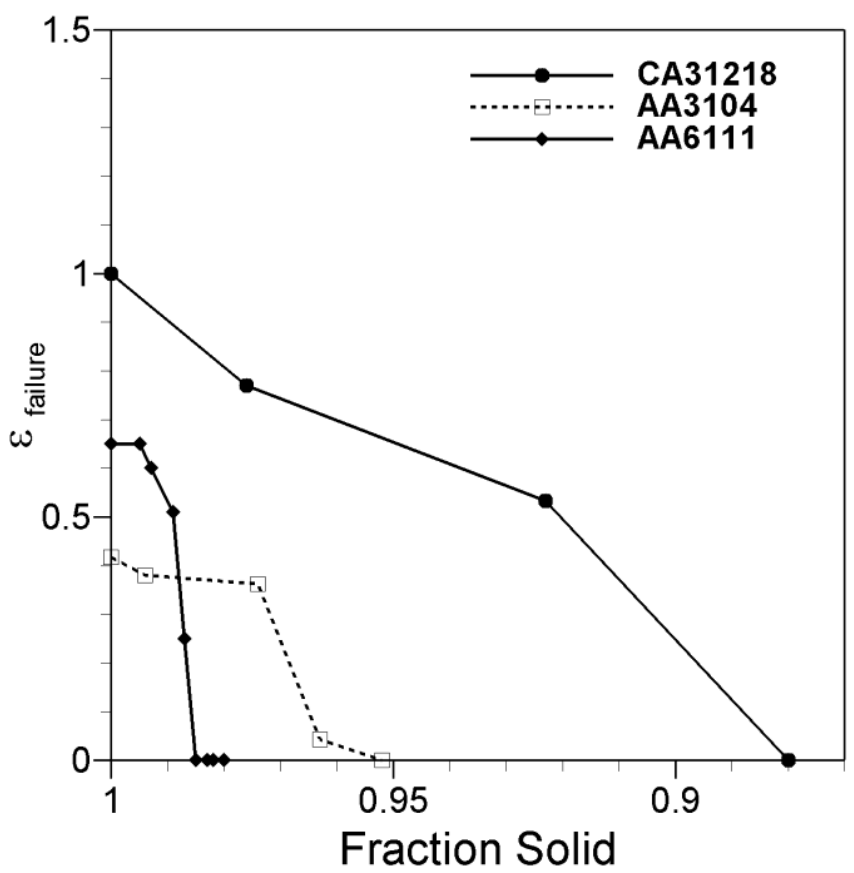

a)

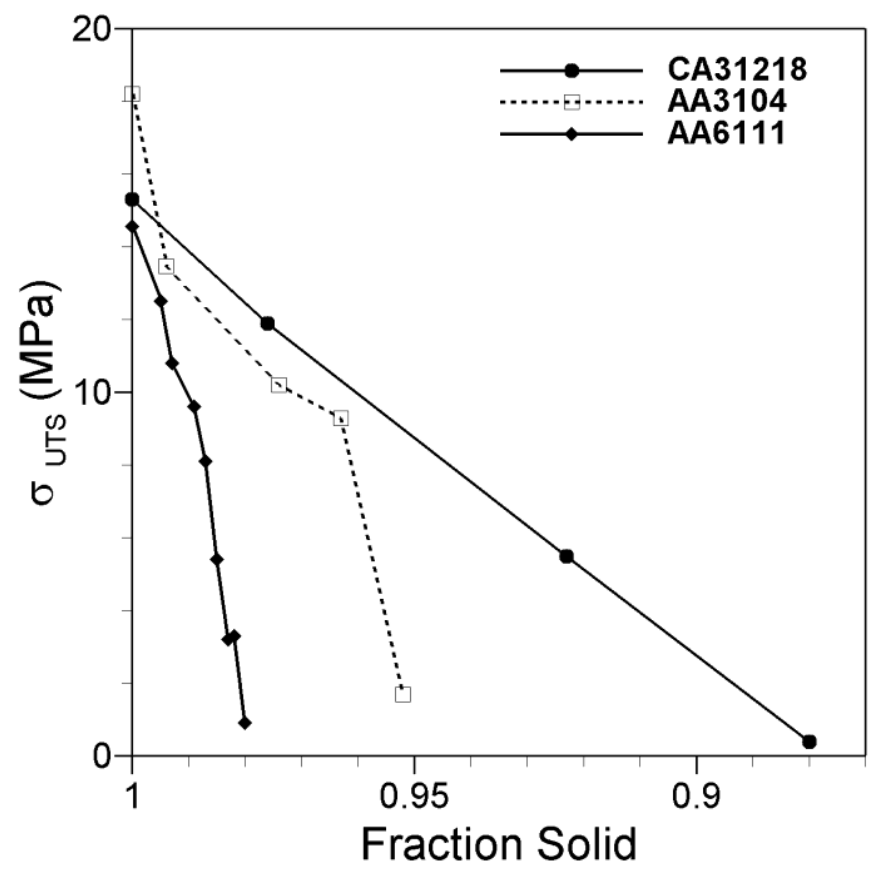

b) 


\section{Tables}

Table 1: Composition (wt.\%) of Major Elements

\begin{tabular}{cccccccc}
\hline Alloy & Cu & Fe & Mg & Mn & Si & Cr & Ti \\
\hline AA3104 & $0.05-0.25$ & $<0.80$ & $0.80-1.30$ & $0.80-1.40$ & $<0.60$ & - & - \\
AA6111[35] & 0.7 & 0.25 & 0.8 & 0.20 & 0.60 & 0.05 & 0.06 \\
CA31218 & 0.86 & 0.25 & 0.22 & 0.87 & 0.12 & 0.003 & 0.08 \\
\hline
\end{tabular}

Table 2: Critical solidification temperatures $\left({ }^{\circ} \mathrm{C}\right)$ for the Test Alloys ${ }^{[22]}$

\begin{tabular}{cccc}
\hline $\begin{array}{c}\text { Fraction } \\
\text { Solid }\end{array}$ & AA3104 & AA6111 & CA31218* $^{*}$ \\
\hline 0 & 649 & 651 & 655 \\
0.80 & 636 & 633 & 640 \\
0.90 & 628 & 619 & 627 \\
0.95 & 616 & 600 & 605 \\
0.98 & 591 & 587 & 548 \\
1.0 & 573 & 483 & 520 \\
\hline
\end{tabular}

*The values for CA31218 were calculated using Thermo-Calc

Table 3: Critical Stress and Ductility Temperatures and the Brittle Temperature Range for AA3104, AA6111, and CA31218

\begin{tabular}{ccccccc}
\hline \multirow{2}{*}{ Alloy } & \multicolumn{2}{c}{$\begin{array}{c}\text { Critical Ductility } \\
\text { Temperature }\left({ }^{\circ} \mathbf{C}\right)\end{array}$} & \multicolumn{2}{c}{$\begin{array}{c}\text { Critical Stress } \\
\text { Temperature }\left({ }^{\circ} \mathbf{C}\right)\end{array}$} & \multicolumn{2}{c}{ Brittle Temperature } \\
& $\dot{\text { Range }\left(\mathbf{C}^{\circ}\right)}$ \\
& $\dot{\varepsilon} \sim 10^{-3} \mathrm{~s}^{-1}$ & $\dot{\varepsilon} \sim 10^{-4} \mathrm{~s}^{-1}$ & $\dot{\varepsilon} \sim 10^{-3} \mathrm{~s}^{-1}$ & $\dot{\varepsilon} \sim 10^{-4} \mathrm{~s}^{-1}$ & $\dot{\varepsilon} \sim 10^{-3} \mathrm{~s}^{-1}$ & $\dot{\varepsilon} \sim 10^{-4} \mathrm{~s}^{-1}$ \\
\hline AA3104 & 610 & 615 & 620 & 615 & 10 & 0 \\
AA6111 & 530 & 560 & 580 & 580 & 50 & 20 \\
CA31218 & 610 & 630 & 630 & 630 & 20 & 0 \\
\hline
\end{tabular}

\section{References}

[1] J. M. Drezet and M. Rappaz, Metall. Mater. Trans. A 27A (1996) 3214-25.

[2] J. Sengupta, S. L. Cockcroft, D. M. Maijer and A. Larouche, Mater. Sci. Eng. A 397 (2005) 157-77.

[3] M. M'Hamdi, A. Mo and H. G. Fjaer, Metall. Mater. Trans. A 37A (2006) 3069-83.

[4] D. G. Eskin, V. I. Savran and L. Katgerman, Metall. Mater. Trans. A 36A (2005) 1965-76.

[5] H. G. Fjaer and A. Mo, Metall. Trans. B 21 (1990) 1049-61.

[6] J. Du, B. S. J. Kang, K. M. Chang and J. Harris, Light Metals 1998, San Antonio, TX TMS, 1998, p. 1025-30.

[7] D. G. Eskin, Suyitno and L. Katgerman, Prog. Mater. Sci. 49 (2004) 629-711.

[8] A. R. E. Singer and S. A. Cottrel, J. Inst. Metals 73 (1947) 33-54. 
[9] L. J. Colley, M. A. Wells and D. M. Maijer, Mater. Sci. Eng. A 386 (2004) 140-8.

[10] A. B. Phillion, S. L. Cockcroft and P. D. Lee, Mat. Sci. and Eng. A (2008) doi:10.1016/j.msea.2008.01.078.

[11] W. M. van Haaften, W. H. Kool and L. Katgerman, Mater. Sci. Eng. A 336 (2002) 1-6.

[12] M. R. Twite, J. A. Spittle and S. G. R. Brown, Int. J. Forming Process. 7 (1,2) (2004) 23360.

[13] J. Kron and H. Fredriksson, Int. Symp. Liq. Met. \& Casting, Nancy, Fr SF2M-Paris, 2003, p. 393-400.

[14] D. Fabregue, A. Deschamps, M. Suery and J. M. Drezet, Acta Mater. 54 (2006) 5209-20.

[15] J. B. Mitchell, S. L. Cockcroft, D. Viano, C. J. Davidson and D. St John, Metall. Mater. Trans. A 38 (2007) 2503-12.

[16] H. B. Dong, M. R. M. Shin, E. G. Kurum, H. Cama and J. D. Hunt, Metall. Mater. Trans. A 34A (2003) 441-7.

[17] S. Thompson, S. L. Cockcroft and M. A. Wells, Mater. Sci. Techn. 20 (2004) 497-504.

[18] A. L. Dons, E. K. Jensen, Y. Langsrud, E. Tromborg and S. Brusethaug, Metall. Mater. Trans. A 30A (1999) 2135-46.

[19] C. A. Aliravci and M. O. Pekguleryuz, Light Metals 1998, San Antonio, TX TMS, 1998, p. 1087-96.

[20] X. G. Chen and J. Langlais, Mater. Sci. Forum 331-337 (2000) 215-21.

[21] L. Backerud, E. Krol and J. Tamminen, Solidification Characteristics of Aluminum Alloys Volume I: Wrought Alloys. AFS, Des Plaines, IL, 1986.

[22] X. G. Chen, Alcan - Arvida R\&D Centre. (2004).

[23] B. Magnin, L. Maenner, L. Katgerman and S. Engler, Mater. Sci. Forum 217-222 (1996) 1209-14.

[24] M. Braccini, C. L. Martin and M. Suery, Model Casting, Welding \& Adv Solidif Proces IX, Aachen, DM TMS, 2000, p. 18.

[25] J. M. Drezet and G. Eggeler, Scr. Metall. Mater 31 (1994) 757-62.

[26] S. Esmaeili, L. M. Cheng, A. Deschamps, D. J. Lloyd and W. J. Poole, Mater. Sci. Eng. A 319-321 (2003) 461-5.

[27] A. K. Dahle and L. Arnberg, Acta Mater. 45 (1997) 547-59.

[28] I. Farup, M. Rappaz and J. M. Drezet, Acta Mater. 49 (2001) 1261-9.

[29] J. Campbell, Castings. Butterworth Heinemann, 2 ed., 1991.

[30] T. W. Clyne and G. J. Davies, Br. Foundryman 74 (1981) 65-73.

[31] L. Y. Zhao, Baoyin, N. Wang, V. Sahajwalla and R. D. Pehlke, Int. J. Cast Met. Res. 13 (2000) 167-74.

[32] W. S. Pellini, Foundry (1952) 125-37.

[33] D. Fabregue, A. Deschamps, M. Suery and W. J. Poole, Metall. Mater. Trans. A 37A (2006) 1459-67.

[34] A. B. Phillion, P. D. Lee, E. Maire and S. L. Cockcroft, Metall. Mater. Trans. A (2008)

doi:10.1007/s11661-008-9584-4.

[35] H. Proudhon and W. J. Poole, Mater. Sci. Forum 519-521 (2006) 913-8. 